\title{
Difficult to Open or Close
}

National Cancer Institute

\section{Source}

National Cancer Institute. Difficult to Open or Close. NCI Thesaurus. Code C63012.

Problem associated with the use of the device in terms of user experiencing difficulty opening and closing the device, even if the operation is being performed according to labeled instructions for use. 